\title{
Konjenital Diafragma Hernili “Çok Yüksek Riskli" Olguların Geriye Dönük Değerlendirilmesi
}

\author{
Şenol Emre®, Rahşan 0̈zcan $\odot$, Ali Ekber Hakalmaz $\odot$, Gonca Tekant $\odot$, Ergun Erdoğan $\odot$, \\ Sinan Celayir(D)
}

İstanbul Üniversitesi-Cerrahpaşa, Cerrahpaşa Tıp Fakültesi, Çocuk Cerrahisi Anabilim Dalı, Istanbul, Türkiye

Şenol Emre, Uzm. Dr. Rahşan Özcan, Doç. Dr. Ali Ekber Hakalmaz, Uzm. Dr. Gonca Tekant, Prof. Dr. Ergun Erdoğan, Prof. Dr. Sinan Celayir, Prof. Dr.

İletişim:

Uzm. Dr. Şenol Emre

İstanbul Üniversitesi-Cerrahpaşa, Cerrahpaşa Tıp Fakültesi, Çocuk Cerrahisi Anabilim Dalı, Istanbul, Türkiye

Tel: 4143314

E-Posta:dr.senolemre@gmail.com
ÖZET

Amaç: Kongenital diafragma hernili (KDH) "çok yüksek risk olguların tanı ve tedavilerinin geriye donuk değerlendirilmesidir.

Hastalar ve Yöntem: Kliniğimizde 2005-2015 yılları arasında takip ve tedavileri yapılan KDH tanılı olguların kayııtları geriye dönük incelendi. Kliniğimizde 2005 öncesi modifiye ventilasyon indeksi (MVI) 80 ve üzerinde olan olgular yüksek riskli olgular olarak tanımlanmaktaydı. Sonraki dönemde prenatal tanı haftası <28 GH (Gebelik Haftası) olması ve doğumdan hemen sonra entübasyon ihtiyacı olması iki risk faktörü olarak daha eklenmiştir. Bu çalışmada bu üç risk faktörüne de sahip olan olgular "çok yüksek riskli" olgular olarak tanımlandı. Bu olguların prenatal tanı haftaları, doğum haftası ve ağırlıkları, entübasyon zamanları, MVI değerleri, anti pulmoner hipertansif tedavi yöntemleri, operasyon zamanı, operasyon yöntemi ve sağkalım oranları değerlendirildi.

Bulgular: KDH tanilı toplam 67 olgunun 16'sı "çok yüksek riskli" grup olarak değerlendirildi. Prenatal tanı zamanı ortalama 25,2 GH (15-28) idi. Ortalama doğum haftası 37,4 (32-40) GH, ortalama doğum kilosu 2850 (1400-3315) gr idi. Olguların tamamı "doğumdan hemen sonra" entübe edildi. "Çok yuksek riskli" bu grubun ortalama MVI değeri: 111,1(80-267) idi. Tüm olgularda konvansiyonel "gentle ventilasyon" stratejisine ek olarak son dönemde 7 olguda oral Sildenafil ve inhale Nitrik Oksit (iNO) tedavisi de uygulanmışıı. "Çok yüksek riskli" grubun sağkalım oranı $\% 19$ (3/16), cerrahi girişim yapılanlarda $\% 50$ (3/6) bulundu.

Sonuç: KDH'de yüksek risk gruplarının belirlenmesi prognostik öngörü yapılabilmesi açııından önemlidir. Gestasyonel tanı yaşı, doğumdan hemen sonra entübasyon ihtiyacı, MVI indeksi ile belirlediğimiz "çok yüksek riskli" grupta mortalite yüksek olmakla birlikte, Sildenafil ve İnhale Nitrik Oksit (iNO) tedavilerinin sağkalım üzerine olumlu etkileri olabileceği görülmektedir.

Anahtar sözcïkler : Diafragma hernisi, pulmoner hipertansiyon, prenatal tanı, modifiye ventilasyon indeksi

\section{A RETROSPECTIVE EVALUATION OF "VERY HIGH RISK" PATIENTS WITH CONGENITAL DIAPHRAGMATIC HERNIA}

\section{ABSTRACT}

Objective: To evaluate the diagnosis and treatment of "very high-risk" patients with Congenital Diaphragmatic Hernia (CDH).

Patients and Methods: Medical records of the CDH patientstreated in our clinic between the years 2005-2015 were reviewed, retrospectively. Before 2005, patients with 80 and higher a modified ventilation index (MVI) equals to 80 and higher were defined as high-risk patients. Later on, $<28$ weeks of prenatal diagnosis and the need for intubation were added as additional risk factors. In this study, cases with these three risk factors were defined as "very high-risk" patients. The gestational week of prenatal diagnosis, birth week and weight at birth, time of first intubation, MVI values, anti-pulmonary hypertensive treatment choices, operative time (surgery time?) and surgery method and survival rates were evaluated.

Results: Sixteen of the 67 patients with CDH were in the "very high-risk" group. The mean prenatal diagnosis week was 25.2 (15-28) GW. The Mmean birth week was 37.4 (32-40) GW and the mean weight at birth was 2850 (1400-3315)g. All patients were intubated instantly after birth. The Mmean MVI value was 111.1(80-267) for the "very high-risk" group. In addition to the conventional "gentle ventilation" strategy, oral Sildenafil and inhaled Nitric Oxide were administered to seven patients recently. Survival rate was $19 \%(3 / 16)$ in the "very high-risk" group, whereas $50 \%(3 / 6)$ in patients who underwent surgery.

Conclusion: Determination of high-risk groups is of crucial importance in CDH. Herein, risk factors for the "very high-risk" group were determined as following: MVI, prenatal diagnosis week and need for immediate intubation after birth. Despite the high mortality rates obtained, Sildenafil and inhaled Nitric Oxide treatment may have had positive effects on survival rate in this group.

Keywords: Congenital diaphragmatic hernia, pulmonary hypertension, prenatal diagnosis, modified ventilation index
Gönderilme Tarihi : 03 Ağustos 2018

Revizyon Tarihi : 25 Eylül 2018

Kabul Tarihi : $\quad 30$ Eylül 2018 
K onjenital diafrgma hernisi (KDH) yüksek mortalite ve morbidite ile seyreden doğumsal bir patolojidir. KDH'de prognozu belirlemede literatürde birçok risk faktörü tariflenmiştir. Bunlardan en sık kullanılanlar doğum öncesi için prenatal tanı haftası, kafa/akciğer ora$\mathrm{nI}$, karaciğerin pozisyonu, midenin pozisyonu; doğum strası ve sonrası için doğum haftası ve kilosu, APGAR skoru, pulmoner hipertansiyon (PH) , pnömotoraks, ortalama havayolu basıncı (MAP), ortalama ventilasyon indeksi (MVI), eşlik eden anomaliler, defektin tarafı ve çapıdır (1-11).

Kliniğimizde 2005 yılı öncesinde konjenital diafrgma hernisinde başlıca risk faktörü olarak MVI kullanılmaktaydı (12). Ancak MVI, sadece doğum sonrası dönemde propgnozu değerlendirmesinde kullanılabilmektedir. Son dönemlerde prenatal tanının artması, bu olgularda doğum öncesi ve doğum sırasındaki risk faktörlerini de içeren iki prognostik faktörün daha prognoz belirteçlerimiz arasına eklenmesini gerekli kılmıştır. Bu çalışmada bu kriterlerin kullanıldığı ve "Çok yüksek riskli" olarak adlandırdığımız $\mathrm{KDH}^{\prime}$ li olguların takip ve tedavi sonuçları sunulmuştur.

\section{Gereç ve yöntem:}

Bir üniversite hastanesindeki çocuk cerrahisi kliniğimizde 2005-2015 yılları arasında takip ve tedavileri yapılan KDH tanılı olguların kayıtları geriye dönük olarak incelendi. Olguların takip ve tedavileri cerrahi yenidoğan yoğun bakım ünitesinde yapılmıştır. Kliniğimizde ekstracorporeal membrane oxygenation (ECMO), yüksek frekanslı ventilasyon (HFO) ve likid ventilasyon kullanılmamaktadır. Bu nedenle tüm olguların mekanik ventilasyon gereksinimlerinde "gentle ventilation" ilkesi ile takip ve tedavileri yapıldı. Prenatal tanılı tüm olguların doğumuna çocuk cerrahisi ekibi de katılmış olup, APGAR skoru 5 ve altında olan olgular barsak distansiyonunu artırmamak için maskeyle ventile edilmeden entübe edildi. Olgularda sedasyon için Midazolam infüzyonu (0.03-0.1 mg/kg/s), asidozun düzeltilmesi için NaHCO3 infüzyonu ( $24 \mathrm{mEq} / \mathrm{L}$ hedeflenerek) ve inotrop ajan olarak Dopamin infüzyonu $(5-10 \mathrm{mcg} / \mathrm{kg} / \mathrm{dk})$ yapıldı. Ortalama arteryel basıncı Dopamine rağmen yeterli düzeyde yükselmeyen olgularda tedaviye Dobutamin infüzyonu da eklendi ( $5 \mathrm{mcg} / \mathrm{kg} / \mathrm{dk}$ ).

Merkezimizde 2005 öncesi modifiye ventilasyon indeksi (MVI) 80 ve üzerinde olan olgular yüksek riskli olgular olarak tanımlanmaktaydı. Sonraki dönemde prenatal tanı haftasının <28 gebelik haftası (GH) olması ve doğumdan hemen sonra entübasyon ihtiyacı olması iki risk faktörü olarak daha eklenmiştir. Bu çalışmada bu üç risk faktörüne de sahip olan olgular "çok yüksek riskli" olgular olarak tanımlanarak değerlendirilmiştir (Şekil 1).

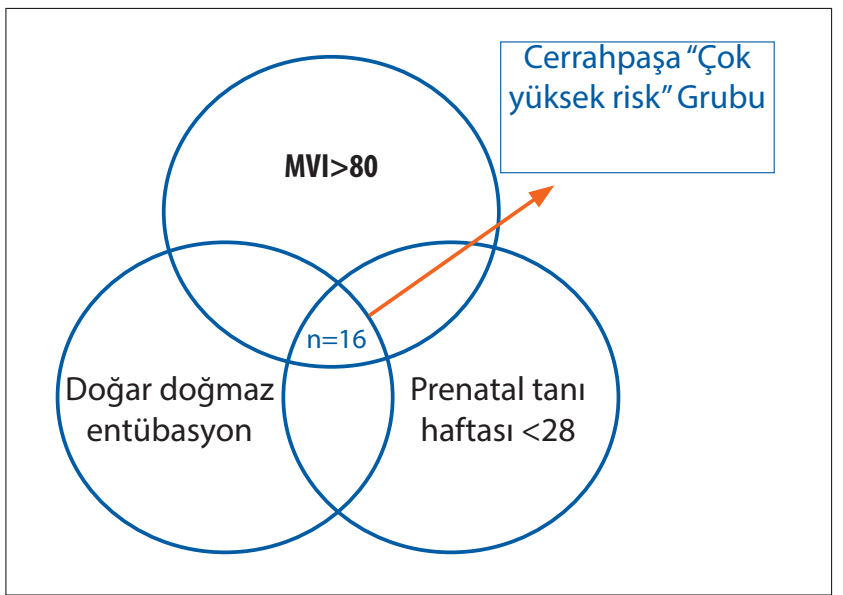

Şekil 1: Cerrahpaşa KDH çok yüksek risk grubu, her üç risk faktörünü de içeren 16 olguyu içerir.

Bu olguların prenatal tanı haftaları, doğum haftası ve ağırlıkları, entübasyon zamanları, MVI değerleri, anti pulmoner hipertansif tedavi yöntemleri, operasyon zamanı, operasyon yöntemi ve sağkalım oranları değerlendirildi.

\section{Bulgular}

KDH tanılı toplam 67 olgunun 16'sı "çok yüksek riskli" grup olarak değerlendirildi. Prenatal tanı zamanı ortalama 25,2 GH (15-28 GH) idi. Ortalama doğum haftası 37,4 GH (3240) GH, ortalama doğum kilosu $2850 \mathrm{gr}$ (1400-3315gr) idi. Ortalama 5.dakika APGAR skoru 4,7 (0-6) olan olguların tamamı "doğumdan hemen sonra" entübe edildi. Ortalama MVI değeri: 111,1 (80-267) idi.

Altı olguda ek anomali ve perinatal sorunlar bulunmakta idi. İki olguda prematürite, bir olguda eşlik eden omfalosel, bir olguda geniş ventriküler septal defekt, bir olguda komplet atrioventriküler septum defekti bulunmaktaydı. Bir olgu ise preeklamptik anne bebeği idi.

Tüm olgularda konvansiyonel "gentle ventilasyon" stratejisine ek olarak son dönemde 7 olguda oral Sildenafil $(0,4$ $\mathrm{mg} / \mathrm{kg} / \mathrm{doz} 3 \mathrm{dozda}$ ) ve inhale Nitrik Oksit (iNO) (22-28 PPM) tedavisi de uygulanmıştı.

10 olgu operasyon aşamasına gelemeden kaybedildi, oratalama hastanede yatış süresi 2,4 gün (1-13gün) idi. Bu olgulardan 3'ünde (\%30) oral Sildenafil ve inhale Nitrik Oksit tedavisi yapılmıştı. Operasyon aşamasına gelebilen 6 olgunun 4'ünde (\%66) oral Sildenafil ve inhale Nitrik Oksit tedavisi yapılmıştı. 6 olgunun ortalama ameliyat yaşı postnatal 9,2 gün (4 gün-15 gün) olup 3'ü sağ, 3'ü sol KDH'li idi. 5 olguda primer onarım, sol diafragma hernili 1 olguda ise mesh ile onarım uygulandı. Primer onarım yapılan bir 
sol KDH'li olguda takipte nüks gelişti. Bu olgu operasyon sonrası 6.ayda mesh ile yeniden onarıldı. Taburcu edilebilen olgularda ortalama hastanede kalış süresi 74,3 (31-152 gün) gün idi.

"Çok yüksek riskli" 16 olguda sağkalım oranı \%19 (3/16) olup cerrahi girişim yapılanlarda \%50 (3/6) bulundu. Hastalarin demografik özellikleri, ve operasyon taraf ve sonuçları Tablo 1'de özetlenmiştir (Tablo 1).

\section{Tartışma}

Konjenital diyafragma hernisi prognoz belirteçleri açısından bakıldığında çok değişkenlik gösterebilir. Gerek risk gruplarının belirlenmesinde kullanılan parametrelerin, gerekse olguların seçimi açısından bakıldığında ise herkes tarafından kabul edilen uluslararası bir prognoz belirteci mevcut değildir (13). Bu nedenlerle güncel kullanımda olan prognoz belirteçleri sıklıkla uygulayıcıların elinde olan olanaklarla ilgili olarak belirlenmektedir. Örneğin bir klinikte ECMO kullanımı varsa, bu durumda prognoz açısından ECMO uygulamasıyla ilgili parametreleri içeren bir prognoz belirteçinin kullanılması daha akılcıdır.
Kliniğimizde $\mathrm{KDH}$ olgularda kullanılabilecek tedavi olasılıkları açısından çerçeve belirlenirken, tam donanımlı bir 3.düzey yenidoğan cerrahisi yoğun bakım ünitesi olmasına karşın ECMO uygulamasının hastanede olmaması prognoz belirteçlerini kliniğimiz olanaklarına göre belirlememizdeki ana faktörlerdir. Bu durum, yüksek riskli olgularda erken ECMO olasığını ortadan kaldırdığı gibi; erken cerrahinin de doğru bir seçim olamadığı belirlendiğinden, ek ya da alternatif medikal önlemlerin kullanılmasını gerekli kılar.

Geriye dönük olarak hastaları değerlendirirken dikkatimizi çeken ve prognoz belirteci olarak kullanmaya başladığımız bu 3 belirteç ile yüksek risk grubunda 16 olgu bulunmaktadır. Bu grupta cerrahisiz 10, cerrahi sonrası 3 olmak üzere toplam 13 olgu kaybedilmiştir. Sağkalım açısından normalde kaybedilme olasılığı olan bu grupta, 6 olgu cerrahi tedavi edilebilir aşamaya gelebilmiş ve ameliyat edilen 6 olgudan 3 olgu yaşamıştır.

"Cerrahpaşa" KDH Risk Kriterleri olarak kullanılan bu parametrelerin ikisininin de (prenatal tanı zamanı ve erken

Tablo 1. Olgulara ait demografik özellikleri, operasyon taraf ve sonuçlarını gösteren tablo.

\begin{tabular}{|c|c|c|c|c|c|c|c|c|c|c|c|c|c|}
\hline Olgu & Cinsiyet & $\begin{array}{l}\text { Doğum } \\
\text { Haftası }\end{array}$ & $\begin{array}{l}\text { Doğum } \\
\text { Kilosu }\end{array}$ & $\begin{array}{l}\text { Prenatal } \\
\text { tanı haftası }\end{array}$ & $\begin{array}{l}\text { Ek anomali/ } \\
\text { sorun }\end{array}$ & Tarafı & MVI & Dobutamin & NO & Sildenafil & Operasyon & Sonuç & $\begin{array}{l}\text { Hastanede } \\
\text { kalıs süresi }\end{array}$ \\
\hline 1 & $E$ & 37 & 3030 & 28 & & Sol & 145 & - & - & & - & Ölüm & 0 \\
\hline 2 & $E$ & 38 & 3140 & 18 & $\begin{array}{c}\text { Annede } \\
\text { preeklampsi }\end{array}$ & Sol & 88 & - & - & & - & Ölüm & 0 \\
\hline 3 & K & 39 & 3030 & 26 & & Sol & 140 & - & - & & - & Ölüm & 0 \\
\hline 4 & K & 40 & 3300 & 28 & & Sol & 94 & - & - & & - & Ölüm & 1 \\
\hline 5 & $E$ & 40 & 3230 & 28 & Omfalosel & Sol & 103 & - & - & & - & Ölüm & 0 \\
\hline 6 & $E$ & 39 & 2940 & 28 & Geniş VSD & Sol & 100 & - & - & & - & Ölüm & 0 \\
\hline 7 & $E$ & 35 & 2600 & 24 & AVSD & Sağ & 80 & - & - & & - & Ölüm & 2 \\
\hline 8 & $E$ & 37 & 2910 & 26 & & Sol & 81 & - & - & & - & Ölüm & 2 \\
\hline 9 & K & 33 & 1870 & 24 & & Sağ & 141 & + & + & + & $\begin{array}{l}\text { Primer } \\
\text { onarım }\end{array}$ & $\begin{array}{l}\text { Nüks- } \\
\text { Yaşıyor }\end{array}$ & 152 \\
\hline 10 & $E$ & 32 & 1400 & 15 & & Sol & 100 & + & + & + & - & Ölüm & 6 \\
\hline 11 & K & 38 & 3080 & 28 & & Sağ & 84 & - & + & + & $\begin{array}{l}\text { Primer } \\
\text { Onarım }\end{array}$ & Ölüm & 28 \\
\hline 12 & K & 38 & 2945 & 26 & & Sol & 267 & + & + & + & - & Ölüm & 1 \\
\hline 13 & $E$ & 38 & 2910 & 28 & & Sol & 80 & - & - & - & $\begin{array}{l}\text { Primer } \\
\text { onarım }\end{array}$ & Ölüm & 21 \\
\hline 14 & K & 36 & 2880 & 28 & & Sağ & 81 & + & + & + & $\begin{array}{l}\text { Primer } \\
\text { onarım }\end{array}$ & Yaşıyor & 22 \\
\hline 15 & $E$ & 40 & 3315 & 28 & & Sol & 84 & + & + & + & $\begin{array}{l}\text { Mesh ile } \\
\text { onarım }\end{array}$ & Yaşıyor & 72 \\
\hline 16 & K & 38 & 3030 & 20 & & Sol & 110 & + & + & + & $\begin{array}{l}\text { Primer } \\
\text { Onarım }\end{array}$ & Ölüm & 11 \\
\hline
\end{tabular}


entübasyon gereksinimi) değişken özellikleri yoktur ve değerlendirmesi kolaydır. Son kriterimiz olarak kullanılan MVI ise hastaya ve klinik durumunun dinamiklerine uygun veri elde etme imkanı veren, erken entübasyon sonrası ilk saatte alındığından prognoz kötü olarak saptandığında ek alternatifleri de erken kulanma şansı veren belirteçlerdir (12).

Prenatal tanı konulmuş olgularda fetal cerrahi girişim zamanlaması için literatürde belirlenen dönem 26-28. haftalar arasıdır $(14,15)$. Merkezimizde fetal cerrahi (Fetal trakeal okluzyon (FETO) vb.) uygulanmaması nedeniyle bu olgular gebelik sürecinde girişim yapılmadan takip edilmektedir. Bu nedenle 28.gebelik haftası öncesi konulan prenatal tanı bir risk belirteci olarak düşünülmüştür.

Sonuçta doğum öncesi riski bilinen (1. Belirteç), doğumdan hemen sonra entübasyon gereksinimi olması ile bunu belli eden (2. Belirteç) bir olguda elinizdeki imkanlar ECMO ya izin vermiyorsa konvasyonel mekanik ventilasyon kriterlerini esas alan MVI (3. Belirteç) doğum sonrası ilk 6 saat içinde kötü gitme olasılığı yüksek $\mathrm{KDH}$ bebekleri belirlemekte ve Sildenafil ve İnhale Nitrik Oksit (iNO) tedavilerini başlama imkanı vermektedir. Bu belirtilen ilaçlar, tedavi grubumuzda 16 olgudan 6'sının cerrahi girişim uygulanabilme aşamasına gelmesini sağlamış ve bunlardan 3 olgu da yaşamda kalmıştır (Şekil 2). Bu bulgular bize tanımlanan 3 belirtecin etkin bir pratik prognostik KDH risk belirteçi olarak değerlendirilmesi gerektirdiğini düşündürmüştür.
Çalışmanın eksileri; değerlendirmenin geriye dönük bir çalışma olması ve kontrol grubunun olmamasıdır. Klinikte konjenital diyafragma hernisinde yüksek riskli olarak değerlendirilen bu grupta kullandığımız alternatif Sildenafil ve İnhale Nitrik Oksit (iNO) tedavileri ile ilgili ilk bulgular çok olumlu olmasa da, bu çalışmanın ileriye dönük ve prospektif ek çalışmalarla desteklenmesini gerekli kılmaktadır.

Normal şartlarda ek medikal tedavi uygulanmaması durumunda yüksek oranda mortalite beklenen bu grup olgularda bazı hastaların yaşamış olması, kullanılan bu yeni "lokal değerlendirme yönteminin ileriye yönelik olarak, pratikte yüksek riskli olgularda ek tedavi yöntemlerinin erken uygulamaya konulmasını sağlayarak sağkalım üzerine olumlu etkileri olması beklenebilir.

Sonuç olarak; KDH'de yüksek risk gruplarının belirlenmesi prognostik öngörü yapılabilmesi açısından önemlidir. Klinik uygulamamızda olguların prognoz açısından ön değerlendirmesinde "Cerrahpaşa" KDH Çok Yüksek Risk Kriterleri" olarak tanımladığımız 3 parametre kullanılmaktadır. Bunlar: 28.gebelik haftası öncesinde tanı konulmuş olması; 5'ten düşük APGAR skoru nedeniyle doğar doğmaz entübasyon ihtiyacı olması, ve MVI değerinin 80'in üzerinde olmasıdır. Bu belirteçlerin kullanıldığı ve yüksek mortalite beklenen $\mathrm{KDH}^{\prime} \mathrm{li}$ "çok yüksek riskli" olgu grubunda cerrahi öncesi uygulanan Sildenafil ve İnhale Nitrik Oksit (iNO) tedavilerinin sağkalım üzerine olumlu etkileri olabileceği izlenimini vermiştir.

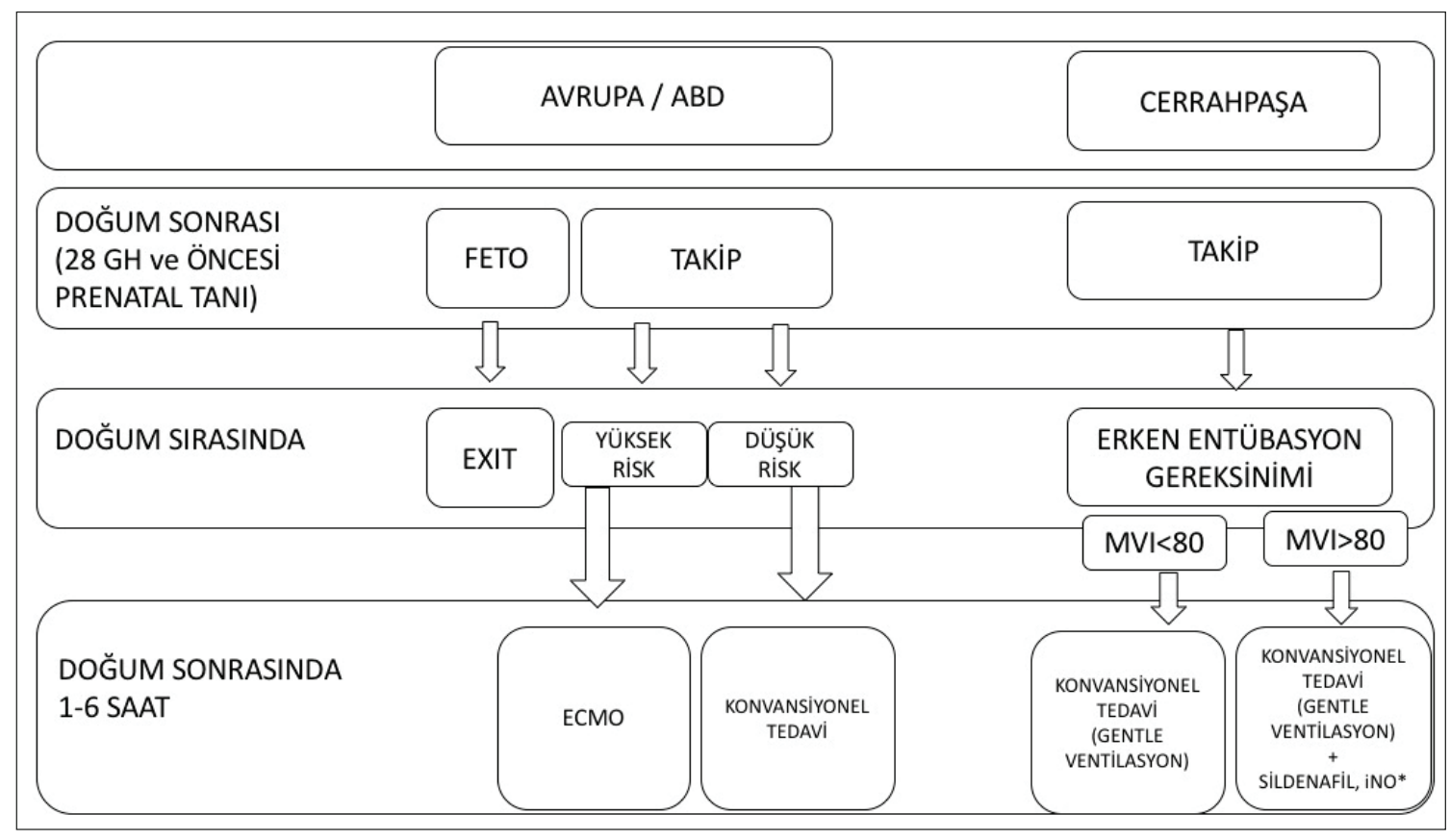

Şekil 2: KDH'de Cerrahpaşa risk belirteçlerine göre kıyaslamalı tedavi yaklaşımları 


\section{Kaynaklar}

1. The congenital diaphragmatic hernia study group. Estimating disease severity of congenital diaphragmatic hernia in the first 5 minutes of life. J Pediatr Surg 2001; 36: 141-5.

2. The Congenital Diaphragmatic Hernia Study Group. Treatment evolution in high-risk congenital diaphragmatic hernia ten year's experience with diaphragmatic agenesis. Ann Surg 2006;244:505-13.

3. The congenital diaphragmatic hernia study group. Defect size determines survival in infants with congenital diaphragmatic hernia. Pediatrics 2007; 120: e651-7.

4. Weinstein S, Stolar CJ. Newborn surgical emergency, congenital diaphragmatic hernia and extracorporeal membrane oxygenation. Pediatr Clin North Am 1993; 40: 1315-33.

5. Wenstrom KD, Weiner CP, Hanson JW. A five-year statewide experience with congenital diaphragmatic hernia. Am J Obstet Gynecol 1991; 165: 838-42.

6. Langham Jr MR, Kays DW, Ledbetter DJ, Frentzen B, Sanford LL, Richards DS. Congenital diaphragmatic hernia: epidemiology and outcome. Clin Perinatol 1996; 23: 671-88.

7. Levison J, Halliday R, Holland AJ, Walker K, Williams G, Shi E, et al, and Neonatal intensive care units study of the NSW pregnancy and newborn services network. A population-based study of congenital diaphragmatic hernia outcome in New South Wales and the Australian Capital Territory, Australia, 1992-2001. J Pediatr Surg 2006; 41:1049-53.
8. Rohana J, Boo NY, Thambidorai CR. Early outcome of congenital diaphragmatic hernia in a Malaysian tertiary center. Singapore Med J 2008; 49: 142-4.

9. Ruano R, Bunduki V, Silva MM, Yoshizaki CT, Tanuri U, Macksoud JG, et al. Prenatal diagnosis and perinatal outcome of 38 cases with congenital diaphragmatic hernia: 8-year experience of a tertiary Brazilian center. Clinics 2006; 61: 197-202.

10. Datin-Dorriere V, Walter-Nicolet E, Rousseau V, Taupin P, Benachi $A$, Parat $S$, et al. Experience in the management of eighty-two newborns with congenital diaphragmatic hernia treated with highfrequency oscillatory ventilation and delayed surgery without the use of extracorporeal membrane oxygenation. J Intensive Care Med 2008; 23: 128-35.

11. Brown RA, Bosenberg AT. Evolving management of congenital diaphragmatic hernia. Pediatr Anesth 2007; 17: 713-9

12. Ilce Z, Celayir S. Modified Ventilatory Index (MVI) in newborns with congenital diaphragmatic hernia (CDH). Indian Pediatr. 2003; 40: 920

13. dos Santos LR, Maksoud-Filho JG, Tannuri U, Andrade WC, Maksoud JG. Prognostic factors and survival in neonates with congenital diaphragmatic hernia. J Pediatr (Rio J). 2003 Jan-Feb;79:81-6.

14. Deprest J, Jani J, Van Schoubroeck D, Cannie M, Gallot D, Dymarkowski S, et al. Current consequences of prenatal diagnosis of congenital diaphragmatic hernia. J Pediatr Surg. 2006; 41: 423-30.

15. Jain V, Agarwala S, Bhatnagar V. Recent advances in the management of congenital diaphragmatic hernia. Indian J Pediatr. 2010; 77:673-8. 